\title{
Economic Advantage of In-Country Utilization of Nigeria Crude Oil
}

\author{
Emeka Emmanuel Okoro', Adewale Dosunmu ${ }^{2}$, Kevin Igwilo', Paul A. L. Anawe ${ }^{1}$, \\ Angela 0. Mamudu ${ }^{3}$
}

${ }^{1}$ Petroleum Engineering Department, Covenant University, Ota, Nigeria

${ }^{2}$ Petroleum Engineering Department, University of Port Harcourt, Port Harcourt, Nigeria

${ }^{3}$ Chemical Engineering Department, Covenant University, Ota, Nigeria

Email: emeka.okoro@covenantuniversity.edu.ng

How to cite this paper: Okoro, E.E., Dosunmu, A., Igwilo, K., Anawe, P.A.L. and Mamudu, A.O. (2017) Economic Advantage of In-Country Utilization of Nigeria Crude Oil. Open Journal of Yangtze Gas and Oil, 2, 226-236.

https://doi.org/10.4236/ojogas.2017.24018

Received: May 2, 2017

Accepted: October 27, 2017

Published: October 30, 2017

Copyright $\odot 2017$ by authors and Scientific Research Publishing Inc. This work is licensed under the Creative Commons Attribution International License (CC BY 4.0).

http://creativecommons.org/licenses/by/4.0/

\begin{abstract}
Crude oil refining is a unique and important link in the supply chain of petroleum products from the wellhead to the end user. Refining adds value through conversion of crude oil and other flows into dozens of co-refined products. Nigeria is probably the largest importer of refined petroleum products on the continent, creating a lucrative refinery market in Europe and the United States. Subsidies have also contributed to the low capacity utilization in our refineries. The current situation of the four National refineries and high dependency on crude oil proceeds has made Nigeria government a full time exporter of crude oil. Because of our population, the demand for refined products which are imported in foreign currency have induced pressure on our local currency; thus, presenting a large cost to the economy. Instead of looking for international crude oil traders or embarking on discounted sales of our sweet crude in this era of low crude oil price, it will be profitable to utilize this crude oil in Nigeria. We will not only export the raw crude but also enrich our petrochemical industries and agricultural sector with the byproducts or co-products from its refining. Investment in petrochemical industry will really bring about an astounding effect in our economy because of enlargement of private domain which will usher new phase of life by reducing inequalities in the nation's income. There has never been a doubt about the large size of the Nigerian market for refined crude oil and petrochemical products. As more countries are discovering crude oil, Nigeria's crude oil export will gradually drop leaving us with excess crude oil instead of excess crude account. There is a need for government to develop industrial sectors that support or leverage its energy resources. The actualization will make it possible for Nigeria to change from raw material supplier to value-added product supplier.
\end{abstract}




\section{Keywords}

Crude Oil, Refineries, Refining and Petrochemicals

\section{Introduction}

Crude oil refining is a unique and fundamental link in the crude oil supply chain from the wellhead to the pump. Refined crude oil adds value in a range of refined products, including transport fuels. The main economic purpose of refining is to maximize value in the conversion of crude oil to finished Petroleum products [1].

Crude oil refineries are large production facilities and high capital intensity, with extremely complex processing schemes. Figure 1 illustrates the oil production, demand for refined products and the output of refined product in Africa. Refineries are used to refine crude oils and other streams of co-products including gasoline, fuel, liquefied petroleum gas (LPG), kerosene, diesel, petrochemical oil, oils and lubricants, asphalt. Of these, transport fuels have higher value; Fuel oils and asphalt have the lowest value [1].

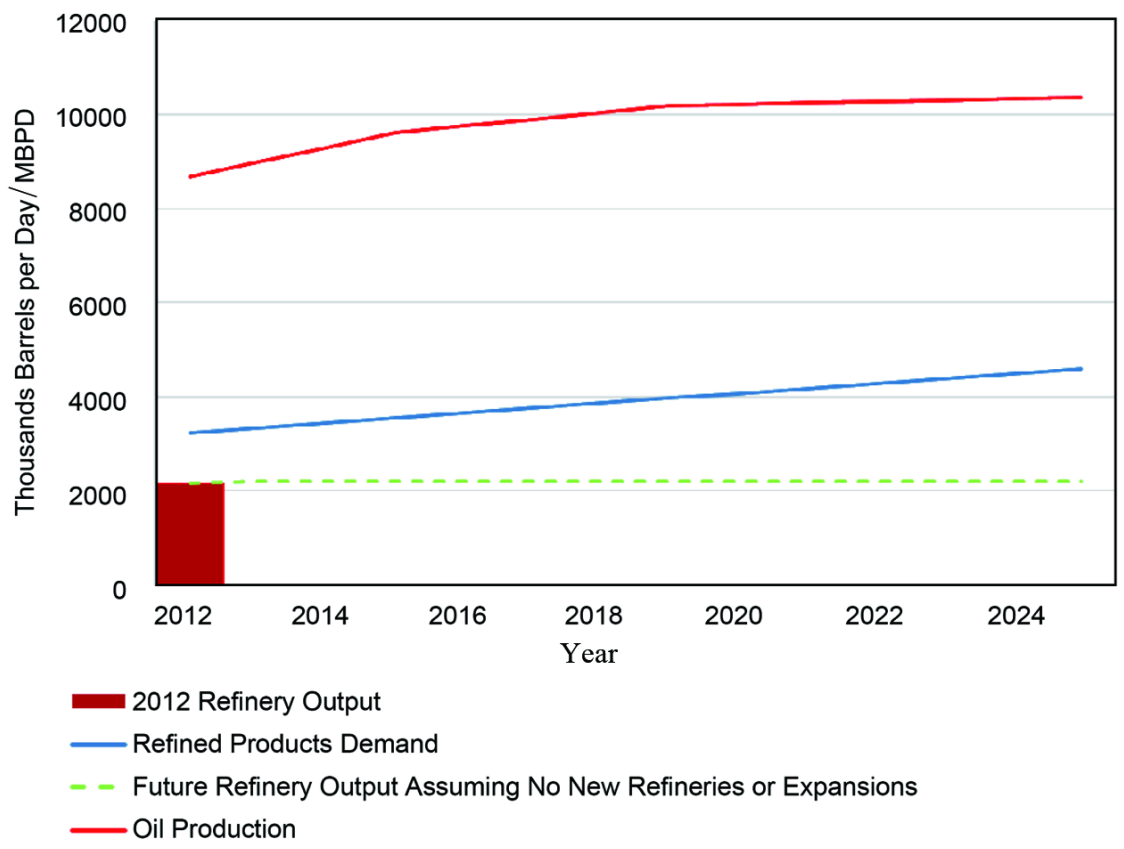

Figure 1. Oil production, demand and refinery output in Africa [4].

Currently there are five (5) refineries in Nigeria; of which four (4) plants are owned by the Government of Nigeria through the Nigerian National Petroleum Corporation (NNPC), while the other is owned and operated by Niger Delta Petroleum Resources. Apart from the unique petrochemical plant, two of the refining plants, Kaduna Refining and Petrochemical Company (KRPC) and Warri Refining and Petrochemical Company (WRPC) complexes have to use their in- 
termediate refinery products to produce petrochemical precursors [2].

Nigeria's four refineries operated on average of 10.46 percent of its combined capacity of 445,000 barrels per day according to the December 2016 report of the NNPC. Average daily sales of refined products in 2016 were 24.24 million liter for gasoline, while the average daily diesel sales and kerosene were 1.06 million liters and 3.12 million liters respectively [2].

Exports of raw crude oil (petroleum and natural gas) are the factors behind Nigeria's growth and account for $91 \%$ of total exports. In $201443 \%$ of total sales were in Europe; 29\% Asia; 12\% Africa and 13\% America [3].

Nigeria is arguably the biggest importer of refined petroleum products on the continent, creating a lucrative market for refineries particularly in Europe and the United States. The Nigerian National Petroleum Corporation (NNPC) spends US $\$ 16 \mathrm{~m}$ to $\$ 20 \mathrm{~m}$ dollars per day on fuel imports. This amounts to about $\$ 1.9$ bn dollars per quarter [5]. Each refinery has a physical configuration and operating characteristics and unique economics. Configuration and performance of a refinery is primarily determined by the refinery location, age, availability of funds for investment, first available demand for products (local and/or export), product quality requirements, specifications and requirements for refined products [4].

According to Dr. Peter Ozo-Eson, "Our domestic refineries must be made to work. Appropriate incentives need to be worked out to attract new investment in refining. While domestic refining by itself is not sufficient to guarantee product price stability, there are clear gains to be derived from domestic refining as opposed to imports."

"Subsidies have also contributed to low capacity utilization at refineries. In Nigeria, for example, current subsidy schemes lead producers to sell crude overseas rather than to local refineries and therefore add to increasing volumes of refined product imports, which present a large cost to the economy", said KPMG in its 2014 Africa Oil and Gas Report, while noting that problems in the refining industry on the continent include corruption, poor maintenance, theft, and operational problems.

According to the report in Special Issue on Business and Social Science, inflation has become so serious and contentions a problem so serious and contentious a problem in Nigeria. Though inflation rate is not new in the Nigeria economic history, the recent rates of inflation in two digits have been a cause of great concern to many. From literatures, inflation in Nigeria can be attributed to two related factors; which are:

1) The way Nigeria organizes and conducts the production and exchange of goods and services in the country and,

2) The policies Nigeria uses to sustain her chosen system of production.

Thus, this study tend to provide an insight on clear gains to be derived from domestic or in-country utilization of Nigerian Crude Oil as this will increase production of goods and service which is the most effective solution to inflations. 


\section{Understanding Crude Oil Processing Business}

Knowing the refining value of crude oil requires a complete description of crude oil and its components, which means that there are many properties. In contrast, the characteristics particularly useful for rapid classification and comparison of Crude oil: API density (a density measure) and sulfur content (see Table 1).

Table 1. Crude oil classes [4].

\begin{tabular}{ccc}
\hline \multirow{2}{*}{ CRUDE OIL CLASS } & \multicolumn{2}{c}{ PROPERTY RANGE } \\
\cline { 2 - 3 } & GRAVITY /API & SULFUR /Wt. \% \\
\hline Light Sweet & $35-60$ & $0-0.5$ \\
Light Sour & $35-60$ & $>0.5$ \\
Medium Medium Sour & $26-35$ & $0-1.1$ \\
Medium Sour & $26-35$ & $>1.1$ \\
Heavy Sweet & $10-26$ & $0-1.1$ \\
Heavy Sour & $10-26$ & $>1.1$ \\
\hline
\end{tabular}

Deep conversion with a sufficient amount of coking capacity substantially destroys all the oil left in its raw slate and turns them into lighter products. Almost all US refineries are either conversion or deep conversion refiners as well as new refineries in Asia, the Middle East, South America and other areas where rapid demand growth for light products occurs [4].

Therefore, high quality crude oil attracts a higher market price than the average price prevailing for all crude. In other words, light crude has a price premium over heavy acids and crude oils (see Table 2). Light sweet crude has a higher value than heavier and sour Crude oil because; 1) light crude oils have higher natural components entering lighter value products, and 2) sweet crude oils contain less sulfur. Therefore, light sweet crude oil require less energy to process and require less capital to meet the demand for quality products and standards than the heavier, more crude oils.

Table 2. API gravity and sulfur levels of some important crude oils.

\begin{tabular}{|c|c|c|c|c|}
\hline \multirow[b]{2}{*}{ CRUDE OIL } & \multirow[b]{2}{*}{$\begin{array}{l}\text { COUNTRY } \\
\text { OF ORIGIN }\end{array}$} & \multirow[b]{2}{*}{ CRUDE OIL CLASS } & \multicolumn{2}{|c|}{ PROPERTIES } \\
\hline & & & $\begin{array}{c}\text { GRAVITY / } \\
\text { API }\end{array}$ & $\begin{array}{c}\text { SULFUR / } \\
\text { Wt. \% }\end{array}$ \\
\hline Brent & U.K. & Light Sweet & 40.0 & 0.5 \\
\hline West Texas & U.S.A. & Light Sweet & 39.8 & 0.3 \\
\hline Arabian Extra Light Export & Saudi Arabia & Light Sour & 38.1 & 1.1 \\
\hline Forcados Export & Nigeria & Medium Medium Sour & 29.5 & 0.2 \\
\hline Arabian Light Export & Saudi Arabia & Medium Sour & 34.0 & 1.9 \\
\hline Kuwait Export Blend & Kuwait & Medium Sour & 30.9 & 2.5 \\
\hline Maya Heavy Export & Mexico & Heavy Sour & 21.3 & 3.4 \\
\hline
\end{tabular}


Therefore, refiners face a key economic choice to meet product and quality demand standards. One can pay a price for high quality crude oil to capture the economic benefits or incur higher refinery capital investments and higher refining costs to take advantage of relatively lower crude oil prices. But this is not entirely true presently [4].

The appearance of heavy but sweet crude from Angola, which is low in sulfur, but when refined yields a lot of products such as fuel oil and residual fuel; these have changed the demand for light sweet crude. China also has sophisticated and complex refineries that produce medium distillates by distilling heavy crude, causing their refineries to get better margins. Therefore, China ignores the Nigerian crude for now, as their demand for sweet light Crude oil is very low.

According to the US Energy Information Administration, "Nearly 65\% of Angolan oil exports last year went to Asia, $49 \%$ of which went to China". China is not alone in this new discovery, according to some reviews; American appetite for heavy crude has increased in recent years. As many of its refiners are mixing these heavy crude oils with Shale oil, the demand for Canadian, Venezuela and Saudi Arabian Crude oils remained solid. This heavy crude oil is not as expensive as light sweet crude, making its refineries more profitable mixes [6].

Historically much chemistry was based on coal: now industry is now used to chemistry based on hydrocarbons sourced from oil refining activities and natural gas. There is a global search for what are termed "advantaged" feedstocks; advantaged being primarily a function of how cheap they are and secondly of availability. The recent surge of investments in the Middle East based on low-cost ethane is the latest example of this and the domination of methane-based chemistry by low cost gas producers is another [7]. An advantaged feedstock is one that has sufficient availability and low pricing such that it provides an advantaged position for an investor to produce product below the prevailing market price. Crude oil is still the primary source of petrochemicals and there is a well understood pricing position for the crude.

\section{In-Country Utilization of Our Crude Oil}

A report by PricewaterhouseCoopers $(\mathrm{PwC})$ has shown that oil prices could fall by $25 \%-40 \%$ over the next four years as a result of increased production of shale oil and gas in the United States. In light of this report, there is an urgent need for Nigeria to transit from oil and gas export dominated economy to one that increases the value of our natural resources and an excellent balance between consumption and export of refined products for the maximum benefit of the economy.

The good news from this research is that, it's time for us as a country to start exploring other options in petroleum business (Midstream for example). This call is not only for the federal and state government alone but also to individuals that have what it takes to invest in oil and gas business. Beyond byproducts of refining processes, several other useful non fuels can be manufactured by refining crude (Figure 2). 

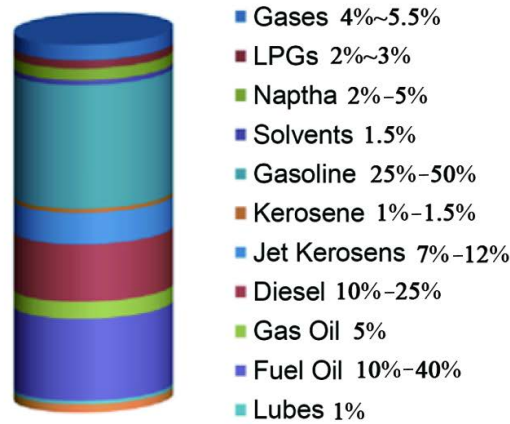

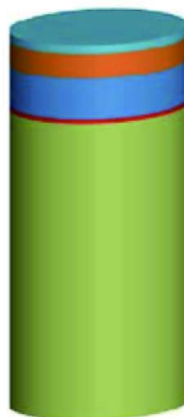

In Roads $2 \%-3 \%$

- Petrochemicals 5\%-7.5\%

- Heat $10 \%-12 \%$

n Lubricants $1 \%$

II Transport $76.5 \%-82 \%$

Figure 2. Output from a single barrel of crude oil [7].

Ethylene is the largest volume of commodity in the petrochemical industry and most of the supply of ethylene that comes from thermal cracking (steam) of hydrocarbons feedstock, such as ethane, propane, naphtha and gas oil. The importance of ethylene as raw material in the petrochemical industry is supported by popular volume demand [8]. In 2013 the United States consumed about 25 million tonnes. Thus, the most important of all petrochemical raw materials is ethylene. The value added to downstream sectors is significant.

The propylene is second in terms of ethylene as a base material for petrochemical production. The largest source of petrochemical propylene is produced as the main by-product of ethylene production [9]. Ethylene plants with liquid feedstock typically produces about $15 \%$ by weight of propylene and produces about $70 \%$ of the propylene consumed by the petrochemical industry. According to reports from Europe, the projection of global demand will increase by more than 40 million tonnes per year to about 175 million tonnes in 2020 and nearly 210 million tonnes in 2025, and most of the growth in demand for end-users comes from China and Other emerging economies [10].

With an increase of $\$ 155.6$ billion in 2013 , the global ethylene market is expected to exceed 248 billion in 2021 [10]. The natural sources for ethylene are Natural gas and Petroleum, instead of planning more than $70 \%$ of our budget on crude oil sales these avenues should be developed in-country so that we can possibly change from raw materials to value added product supplier to the world. The petrochemicals industry will increasingly rely upon the refineries to source for feedstocks. New technologies will be continually developed and other technologies improved that will help ensure that the relationship between refineries and petrochemicals are tied ever closer together [11]. Investment in Petrochemical industry will really bring about an astounding effect in our economy because of enlargement of private domain which will usher new phase of life by reducing inequalities in the nation's income (Figure 3). Nigeria economy has not benefited financial from economic contributions of the petrochemical industry and various products beyond oil and gas that has petrochemicals as a staple. Many of the largest oil producing countries, which have for decades exported crude oil to the more developed areas of the world, which in turn produce higher value added products, are now making investments in the development of their petro- 
chemical production capacity [11]. This aspect of the oil industry has not been fully utilized in Nigeria; Petrochemicals are simply defined as chemicals produced from petroleum. Some petrochemical compounds are available from other fossil fuels such as coal or natural gas wells. Currently, oil and gas are the most important sources of raw materials because they are cheaper, more accessible and can be processed easily from the refineries. Today, many products include gasoline, cosmetics, fertilizers, detergents, synthetic fabrics, asphalt and plastic are made from petrochemicals. Jeannette Goldsmith [12] said that "the US military, petrochemical products played many important roles; from helmets that can stop 9 millimeter rounds to Kevlar fiber to the Army combat uniformly which is worn by every soldier in US Army, which is about 50 percent nylon". And one of the most common life-saving devices in the country, the band (seat-belt) is made of petrochemical products [12]. If deployments are activated in the petrochemical industry, it will make an important contribution to the country's economy, diversifying from our dependence on production and export of crude oil.

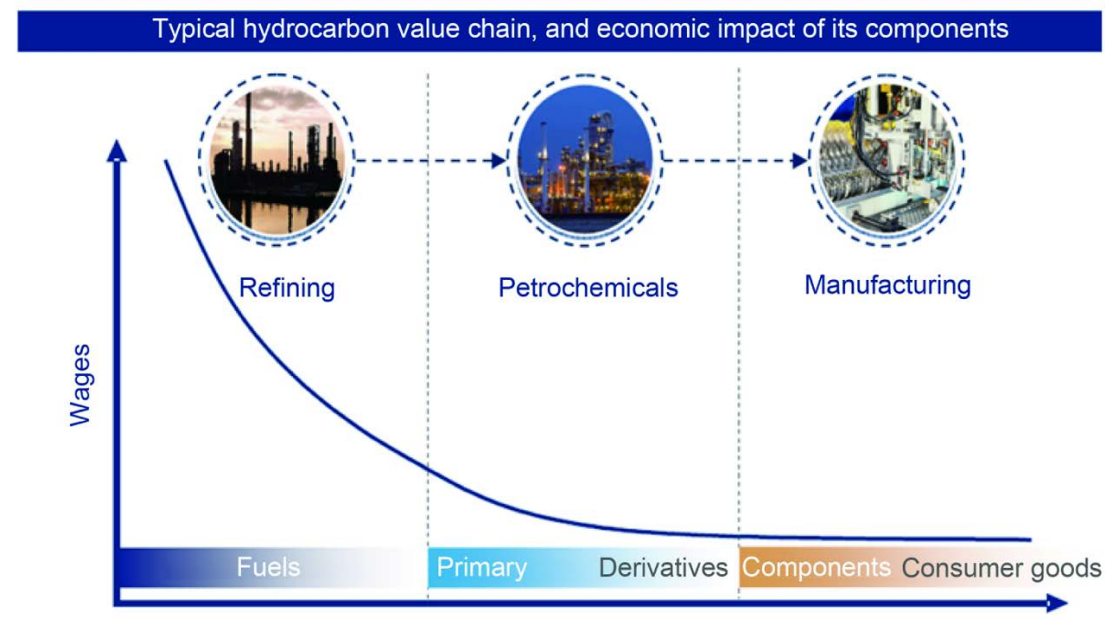

Figure 3. Economic benefits of downstream [8].

The chemical industry in the Middle East currently supports approximately 840,000 jobs: 110,000 in the production of chemicals and indirectly some 730,000 jobs, including suppliers and subcontractors involved in areas such as gas production, outsourced maintenance, transportation and other logistics services. Since job creation and economic diversification have become a more pressing issue in the last decade in Nigeria, if these results and jobs have been created in the country; the contribution from the sector will increasingly be recognized by both Federal and State governments.

Petrochemical investment has contributed to an increase in Qatar's GDP (the sector made some $\$ 9.3 \mathrm{bn}$ in revenues from domestic operations); Qatar's downstream petrochemical sector forms a key pillar to its industrial base, and like the upstream industry; it has maintained robust output despite the depressed global oil prices. One advantage that Qatar has that Nigeria can also 
benefit if we diversify in this direction is the low cost of inputs. Qatar Petrochemical Company (QAPCO) receives hydrocarbons feedstock at favourable rates from its parent company, Qatar Petroleum (QP), boosting the margins it earns on products like low-density polyethylene (LDPE), a common plastic used in machine mouldings and electric cables.

The European chemical industry in 2013 accounted for $16.7 \%$ of sales of chemicals worldwide and created a surplus of EUR 48.7 billion. They consist of 29,000 companies, of which $96 \%$ are small and medium-sized enterprises. It employs 1.16 million people [13]. The petrochemical industry is based on a large part of European production as it is a major source of material for the processing industries that use polymers and synthetic rubber for the production of many products for daily use. These products are also used in many other industries as key production resources, for example in the production of parts for light vehicles, which in turn helps to save energy when the machine is in operation.

The fact is that there are a large number of petrochemical-based products that are impossible to quantify, but which are important components of today's society. The platform can be worth much less than a car, but without a tire, the machine cannot function. This scenario is multiplied many times when all the different products made from petrochemicals are considered.

One of the major challenges that Nigeria may face is low quantity of petrochemicals products due to low capacity utilizations and unavailability of the requisite technology. But this challenge can be tackled by producing petrochemicals that are in increasing demand in the international market. Such chemicals are produced using raw materials that are derived from crude oil and natural gas. Nigeria as a major hydrocarbon producer faced with diversification challenges should follow this good path in other to achieve its economic targets. The Economic Intelligence Group forecasts inflation rate (year-on-year) to ascend to 18.90\% from 9\% reached in May 2015 (Figure 4). According to Anfofum et al. [11], inflation encourages investment and production and as such increase growth in wages and consumption.

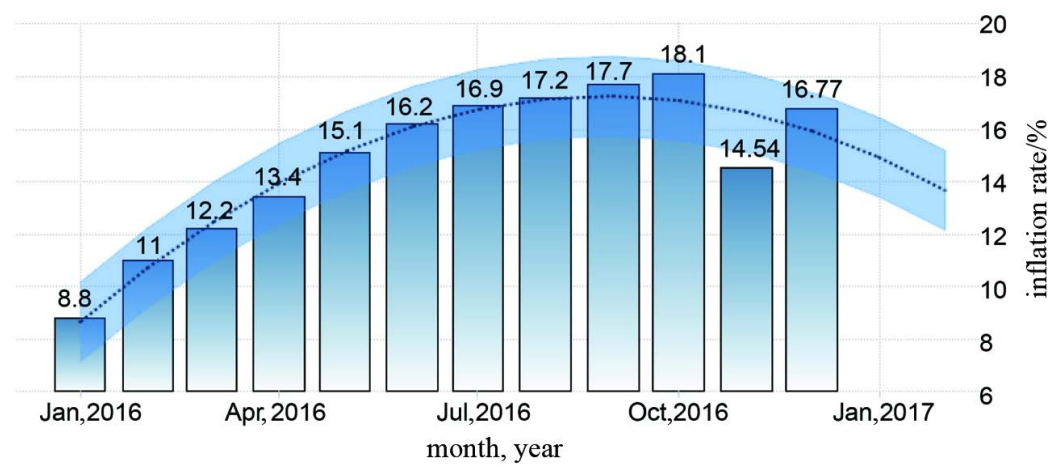

Figure 4. Inflation outlook February 2017 [14].

\section{A New Direction for More Investments In-Country}

Our downstream sector should be made a priority for investment because if this 
is actualized, it will be the strength of our economy and change our status as a "broke" country. Our downstream chemical production and processing capacities need to be expanded and present technologies upgraded in such a way that, $40 \%-50 \%$ of our budgets will be forecast from the revenues generated in petrochemical sector (Figure 5). Two steps in achieving downstream investment growth;

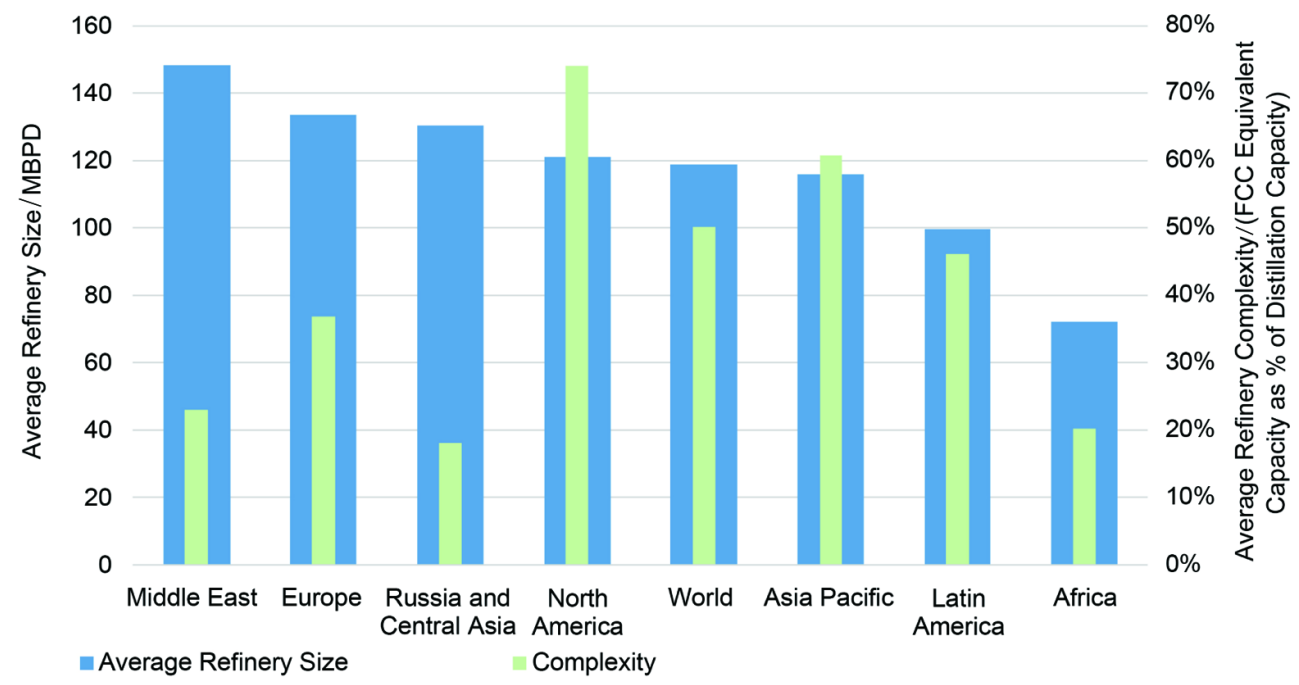

Figure 5. Regional refinery sizes and complexity [4].

1) To identify and capture existing opportunities, such as replacing imports. Nigeria's investment should be channeled in identifying niches for the production of derivatives that can meet local demand. Such derivatives should be where raw materials and energy cost benefits contribute to the profitable results for the end product. Significant opportunities are reported in the processing of plastics for the production of plastic bags.

2) Federal and state governments should identify a company or create the conditions that will make new business potential for further expansion in the industry. A practical example is plastic processing (to make products like vinyl cutter or automotive parts) the potential to create a significant number of jobs, and thus can make a case for government support in this area.

These downstream investment steps can contribute to the success of expanding refining and petrochemicals industry if the country and also change our status from a "broke country" to "economically vibrant country".

\section{Conclusion}

There has never been a doubt about the large size of the Africa/Nigerian market for refined petroleum and petrochemical products. As more countries are discovering oil, Nigeria's crude export will gradually drop leaving us with excess crude instead of excess crude account. As the demand for fuels and feedstocks change, the technologies for refining them must be studied. Conventional me- 
thods for refining heavy feedstocks are already gradually giving way to innovative design. Both energy and chemical markets compete for hydrocarbon molecule demand, low crude oil prices should be utilized by refining in-country and develop our Petrochemical Industry. There is a need for government to develop industrial sectors that support or leverage its energy resources. The Federal Government of Nigeria should encourage in-country refining and development of Petrochemical Industry in the country rather than exporting huge capacity of crude produced. For example, developing downstream plants/facilities that will optimize energy by-products will help establish a portfolio of petrochemicals, chemicals and fertilizer companies. The actualization will make it possible for Nigeria to change from raw materials supplier to value-added product supplier. When this is actualized, we as a country will have a local production of competitive goods which will help appreciate the Nigeria naira currency in relation to major international currencies. This call is not only for the federal and state government alone but also to individuals that have what it takes to invest in oil and gas business.

\section{Acknowledgements}

The authors wish to express their thanks to Department of Petroleum Engineering, Covenant University, and the entire Management of Covenant University Canaan Land Nigeria; for their support and enabling environment to embark on this study.

\section{References}

[1] Searle, S. and Malins, C. (2016) Case Study: The Egyptain Refining Company Project in Cairo. The International Council on Clean Transportation (ICCT), Working Paper 2016-1.

[2] Department of Petroleum (DPR) (2016) Yearly Report. Department of Petroleum, Lagos.

[3] Trading Economics (2017) Nigeria Core Inflation Rate. www.tradingeconomics.com/Nigeria/core-inflation-rate/forecast

[4] Gaffney, Cline and Associate (2014) Will Exploration Success in Africa Lead to New Refineries?

http://gaffney-cline-focus.com/will-exploration-success-in-africa-lead-to-new-refin $\underline{\text { eries }}$

[5] Central Bank of Nigeria Bulletin (2010-2016) History of Inflation since 1988 to date. http://www.cbn.gov.ng/documents/statbulletin.asp

[6] The Commodity Prices Displayed (2014) Trading Economics Based on Over-The-Counter (OTC). The Commodity Prices Displayed, Strasbourg.

[7] The U.S. Energy Information Administration (EIA) (2016) The Annual Energy Outlook (AEO), Presents Long-Term Projections of Energy Supply, Demand, and Prices through 2040. The U.S. Energy Information Administration (EIA), Washington DC.

[8] Andy, A. (2008) Refinery/Petrochemicals Integration: Past, Present and a Look into the Future. Chemicals, Petrochemicals \&Polymers. 9 th International Conference \& 
Exhibition (Petrotech), New Delhi, 15-19 January 2008.

[9] Hirshfeld, D.S. and Jeffrey, A.K. (2012) Analysis of Energy Use and CO Emissions in the U.S. Refining Sector, With Projections for 2025. Environmental Science \& Technology, 46, 3697-3704.

[10] Anfofum, A.A., Afang, H.A. and Danpome, M.G. (2015) Analysis of the Main Determinants of Inflation in Nigeria. Research Journal of Finance and Accounting, 6, 144-155.

[11] "Petrochemicals Europe" Unveiled (2014) What Happens When Raw Materials Get at the Refinery and When Does Petrochemistry Step in?

[12] Petrochemical Europe (2015) EU Economic Development. Petrochemical Europe, France.

[13] Alison-Madueke, D. (2012) Investment Opportunities in Nigeria's Downstream Oil and Gas Value Chain. Nigerian National Petroleum Corporation, Abuja.

[14] National Bureau of Statistics Nigeria (2017) CPI and Inflation Report. www.tradingeconomic.com 